\title{
Standard Test to Measure Knowledge of Cotton Farmers on Health Hazards of Pesticides Usage in Kurnool District of Andhra Pradesh
}

\author{
P. Nagarjuna Reddy* T. Lakshmi** And S.V. Prasad*** \\ Department of Agricultural Extension, S.V. Agricultural College, Tirupati-517 502 \\ Email: nagarjun912@gmail.com
}

\begin{abstract}
The study aimed at determining the farmers' knowledge of the pesticides and their use on the field in Cotton. Fifty items of knowledge on helath hazards of pesticides usage of cotton were selected from a large number of item pool collected based on standard criteria and in consultation with scientists of Regional Agricultural Research Station Tirupati, Subject Matter Specialists, Master Trainers of Acharya N.G. Ranga Agricultural University. Finally 26 items were selected after following the statistical procedures for the construction of standard knowledge test.
\end{abstract}

Keywords: Knowledge, Cotton farmers and Pesticides usage

\section{Introduction}

Farming is one of the most hazardous of all industries, often associated with high rates of occupational injury and illness and agricultural workers can be exposed to several environmental hazards potentially harmful to their health. Increasing pesticide use as the main method of pest control in areas with intensive agriculture, can bring adverse effects as growers may use excessive amounts without adequate protective measures. Even farmers who are aware of the harmful effects of pesticides are sometimes unable to translate this awareness into their practices. Cotton, one of the most intensively sprayed field crops, receives slightly more than $10 \%$ of the total pesticide used annually and covering nearly $25 \%$ of the insecticide sales worldwide. Although cotton accounts for less than about $3 \%$ of the world total cultivated area, it ranks among the crops with the highest input of agrochemicals.

\section{Materials and Methods}

The present investigation was conducted in Kurnool district of Andhra Pradesh during 2013-14. The knowledge test was developed by employing following methodology and the standardization of the test items were given below.

\section{a. Collection and framing of knowledge items}

A large number of items were obtained from the scientists of RARS, Tirupati, Subject Matter Specialists, Master Trainers and field extension workers of Acharya N.G.Ranga Agricultural University and State Department of Agriculture, Andhra Pradesh. Finally 50 items were scrutinized after careful editing to develop standardized knowledge test. By using the above criteria, 50 items were selected for developing knowledge test after carefully editing and by subjecting them to expert scrutiny and was appended in AppendixI.

\section{b. Selection of items}

Content of the test was composed of items asked in the form of questions. The criteria used for selection of items were:

i. Response to items should promote thinking rather than rote memorization.

ii. They should differentiate the well informed respondent from the less informed and should have certain difficulty value.

iii. The items included should cover all areas of knowledge about health hazards of pesticides usage in cotton.

\section{c. Item analysis}

The item analysis was carried out as per the standard procedure, so as to yield three kinds of information viz., "index of item difficulty", "item discrimination index" and "point biserial correlation". The index of the item difficulty reveals how difficult an item is, where as discrimination index indicates the extent to which an item discriminates the well informed individual from the poorly informed. The point biserial correlation provides information on how well an item measures or discriminates with the rest of the test items. 
Pre-testing of the items was done as suggested by Gonard (1948). The items were revised and administered to thirty respondents selected for the purpose of pre-testing in controlled situation. Care was taken to see that thirty respondents for this purpose were outside the main sample selected for the study. The data thus obtained was subjected for item analysis. To analyze 50 items each of the thirty respondents to whom the test items were administered was scored on the basis of the score allotted i.e., 1 for correct response and 0 for incorrect response. After computing the total score obtained by each of the thirty respondents on 50 items, they were arranged in order, from highest to lowest. These thirty respondents were then divided into six equal groups, arranged in descending order of total scores obtained by them. These groups were labeled as $\mathrm{G}_{1}, \mathrm{G}_{2}, \mathrm{G}_{3}$, $\mathrm{G}_{4}, \mathrm{G}_{5}$ and $\mathrm{G}_{6}$ respectively with five respondents in each group. For the purpose of item analysis, the middle two groups $G_{3}$ and $G_{4}$ were eliminated keeping only four extreme groups with high and low scores. The data of correct responses for each of 50 items were tabulated for each of these four groups (Bloom et al.1956)

\section{d. Selection of the items for the final test Item difficulty index $(\mathbf{P})$}

The Item difficulty index for each of 50 items was calculated as the percentage of the respondents answering an item correctly and is presented in Table 1. The items with ' $\mathrm{P}$ ' values ranging from 30 to 70 were considered for the final selection of the standard knowledge test.

\section{Discrimination index $\left(\mathbf{E}^{1 / 3}\right)$}

Discrimination index of each of the 50 items were computed by using the following formula and presented in Table 1.

$$
E^{1 / 3}=\frac{\left(S_{1}-S_{2}\right)-\left(S_{5}-S_{6}\right)}{---}
$$

$S_{1} S_{2}, S_{5}$ and $S_{6}$ are the frequencies of correct answers in the groups $G_{1,} G_{2}$ and $G_{5}$ and $G_{6}$ respectively. ' $\mathrm{N}$ ' is the total number of respondents selected for item analysis, that is thirty. The items with discrimination index ranging from 0.30 to 0.70 were selected for the construction of final knowledge test.

\section{Point biserial correlation (rpbis)}

Point biserial correlation was calculated to work out the internal consistency of the items i.e., relationship of the total score to a dichotomized answer on any given item. It was calculated by using the formula suggested by Garrett (1966).

$$
\mathrm{r} \text { pbis }=\frac{\mathrm{Mp}-\mathrm{Mq}}{\mathrm{SD}} \times V_{\mathrm{pq}}
$$

Where

$\mathrm{r}$ pbis $=$ Point biserial correlation

$\mathrm{Mp}=$ Mean of the total scores of the respondents who answered the item correctly (or)

$\mathrm{Mp}=\underline{\text { Sum of the total of XY }}$

Total number of correct answers

$\mathrm{Mq}=$ Mean of the total scores of the respondents who answered the item incorrectly or

$\mathrm{Mq}=\underline{\text { Sum total of } \mathrm{X}-\text { Sum total of XY }}$

Total number of wrong answers

$\mathrm{SD}=$ Standard deviation of the entire sample

$\mathrm{p}=$ Proportion of the respondents giving correct answer to the item

$\mathrm{q}=$ Proportion of the respondents giving incorrect answer to the item (or) $\mathrm{q}=1-\mathrm{p}$

$\mathrm{X}=$ Total score of the respondent for all the items

$\mathrm{Y}=$ Response of the individual for the items (Correct $=1$; Incorrect $=0$ )

$\mathrm{XY}=$ Total score of the respondent multiplied by the response of the individual to the item.

Items having significant point biserial correlation, either at 1 per cent or 5 per cent level were selected for the final test of the knowledge (Table 1).

To set significance of Point biserial correlation co-efficient the following ' $t$ ' test was used.

$$
t=\frac{r \text { pbis } \sqrt{N-2}}{\sqrt{1-\text { rpbis }^{2}}}
$$


The resulting co-efficient is a product moment correlation co-efficient and is used and interpreted just as the Pearson correlation co- efficient.

\section{e. Total items selected}

Out of 50 items, 26 items pertaining to knowledge of cotton farmers on health hazards of pesticides usage were finally selected comprising of five formats of the test items that are true or false, yes or true, multiple choice, answer the following and fill in the blanks.

\section{f. Reliability of the test}

Split half reliability method was used to find out the reliability. The test was administered to thirty respondents. The two sets of knowledge scores obtained by the farmers were correlated. The correlation $(\mathrm{r}=$ 0.63) was highly significant indicating a high degree of dependability of the test for measuring knowledge of Cotton farmers on health hazards of pesticides usage.

\section{g. Validity of the test}

The validity of the test items was tested by the method of point biserial correlation (rpbis). The items with significant correlation coefficients either at 1 or 5 per cent level were included in the standard knowledge test designed to measure the knowledge of Cotton farmers on health hazards of pesticides usage.

\section{Results and Discussion:}

The results of the knowledge test obtained were as follows in Table-1. Out of 50 items, 26 items were finally selected based on item discrimination index and ' $\mathrm{t}$ ' values obtained. Each of the 26 items in the knowledge test were administered to the respondents in Telugu language and their responses were recorded in the form of correct or incorrect answers. The correct answer was assigned a weightage of 1 and a weightage of "0" was assigned to incorrect answer.

Table.1, Difficulty, Discrimination and Point biserial correlation for knowledge

Test items.

\begin{tabular}{|c|c|c|c|c|c|c|c|c|c|}
\hline \multirow[t]{2}{*}{ S.No } & \multicolumn{4}{|c|}{$\begin{array}{l}\text { Frequencies of } \\
\text { correct answer of } \\
\text { respondents in } \\
\text { four extreme } \\
\text { groups }\end{array}$} & \multirow[t]{2}{*}{$\begin{array}{l}\text { Total s of frequencies } \\
\text { of correct answers by } \\
\text { all six groups } \\
(\mathbf{n}=\mathbf{3 0})\end{array}$} & \multirow[t]{2}{*}{$\begin{array}{l}\text { Difficulty index } P \\
\text { (\% of respondents } \\
\text { giving correct } \\
\text { responses) }\end{array}$} & \multirow[t]{2}{*}{$\begin{array}{l}\text { Discrimination } \\
\text { index }\left(E^{1 / 3}\right)\end{array}$} & \multirow[t]{2}{*}{$\begin{array}{l}\text { Point } \\
\text { biserial } \\
\text { correlation } \\
\text { (rpbis) }\end{array}$} & \multirow[t]{2}{*}{$\begin{array}{c}\text { 't' } \\
\text { Values }\end{array}$} \\
\hline & $\mathrm{G}_{1}$ & $\mathrm{G}_{2}$ & $\mathrm{G}_{5}$ & $\mathrm{G}_{6}$ & & & & & \\
\hline 1 & 3 & 5 & 3 & 1 & 19 & 63.33 & 0.40 & 0.360 & $2.0450 *$ \\
\hline 2 & 1 & 0 & 0 & 0 & 1 & 3.33 & 0.10 & 0.100 & $0.5305 \mathrm{NS}$ \\
\hline 3 & 4 & 5 & 2 & 2 & 19 & 63.33 & 0.50 & 0.445 & $2.6310^{*}$ \\
\hline 4 & 4 & 2 & 1 & 1 & 15 & 50.00 & 0.40 & 0.237 & $2.2710 *$ \\
\hline 5 & 5 & 4 & 1 & 0 & 16 & 53.33 & 0.80 & 0.606 & $4.0306^{* *}$ \\
\hline 6 & 5 & 3 & 3 & 1 & 19 & 63.33 & 0.40 & 0.447 & $2.6431^{*}$ \\
\hline 7 & 5 & 4 & 1 & 0 & 15 & 50.00 & 0.80 & 0.576 & $3.7294 * *$ \\
\hline 8 & 5 & 5 & 2 & 0 & 16 & 53.33 & 0.80 & 0.535 & $3.3511 * *$ \\
\hline 9 & 4 & 3 & 1 & 0 & 11 & 36.67 & 0.60 & 0.257 & $1.4063 \mathrm{NS}$ \\
\hline 10 & 4 & 4 & 3 & 2 & 21 & 70.00 & 0.30 & 0.470 & $2.8167 * *$ \\
\hline 11 & 4 & 4 & 1 & 0 & 16 & 53.33 & 0.70 & 0.507 & $3.1164 * *$ \\
\hline 12 & 4 & 4 & 0 & 0 & 16 & 53.33 & 0.80 & 0.561 & $3.5828 * *$ \\
\hline 13 & 5 & 3 & 1 & 1 & 13 & 43.33 & 0.60 & 0.348 & $2.0837 *$ \\
\hline 14 & 5 & 4 & 2 & 2 & 20 & 66.67 & 0.50 & 0.622 & $4.2041 * *$ \\
\hline 15 & 3 & 2 & 2 & 0 & 11 & 36.37 & 0.30 & 0.160 & $0.8600 \mathrm{NS}$ \\
\hline 16 & 3 & 3 & 1 & 2 & 14 & 46.67 & 0.30 & 0.164 & $0.8774 \mathrm{NS}$ \\
\hline 17 & 4 & 4 & 2 & 0 & 18 & 60.00 & 0.60 & 0.561 & $3.5865^{* *}$ \\
\hline 18 & 4 & 1 & 4 & 0 & 16 & 53.33 & 0.10 & 0.207 & $1.1188 \mathrm{NS}$ \\
\hline 19 & 4 & 3 & 4 & 0 & 15 & 50.00 & 0.30 & 0.242 & $2.1045^{*}$ \\
\hline 20 & 5 & 4 & 0 & 0 & 17 & 56.67 & 0.90 & 0.427 & $2.4987^{*}$ \\
\hline 21 & 5 & 3 & 2 & 0 & 14 & 46.67 & 0.60 & 0.437 & $2.5674^{*}$ \\
\hline 22 & 4 & 3 & 0 & 4 & 18 & 60.00 & 0.30 & 0.087 & $0.4645 \mathrm{NS}$ \\
\hline 23 & 4 & 4 & 1 & 0 & 10 & 33.33 & 0.70 & 0.413 & $2.3996^{*}$ \\
\hline 24 & 4 & 3 & 2 & 3 & 17 & 56.67 & 0.20 & 0.127 & $0.6770 \mathrm{NS}$ \\
\hline 25 & 5 & 2 & 2 & 0 & 15 & 50.00 & 0.50 & 0.414 & $2.4100^{*}$ \\
\hline 26 & 3 & 2 & 2 & 2 & 15 & 50.00 & 0.10 & 0.120 & $0.6411 \mathrm{NS}$ \\
\hline 27 & 5 & 5 & 5 & 1 & 25 & 83.33 & 0.40 & 0.976 & $2.3876^{*}$ \\
\hline 28 & 5 & 4 & 3 & 1 & 20 & 66.67 & 0.50 & 0.619 & $4.1713^{* *}$ \\
\hline 29 & 5 & 3 & 0 & 0 & 16 & 53.33 & 0.80 & 0.693 & $5.0935^{* *}$ \\
\hline 30 & 5 & 4 & 2 & 1 & 18 & 60.00 & 0.60 & 0.574 & $3.7103^{* *} *$ \\
\hline 31 & 5 & 5 & 3 & 2 & 21 & 70.00 & 0.50 & 0.625 & $4.2394^{*} *$ \\
\hline
\end{tabular}


Standard Test to Measure Knowledge of Cotton Farmers on Health Hazards of Pesticides Usage ...

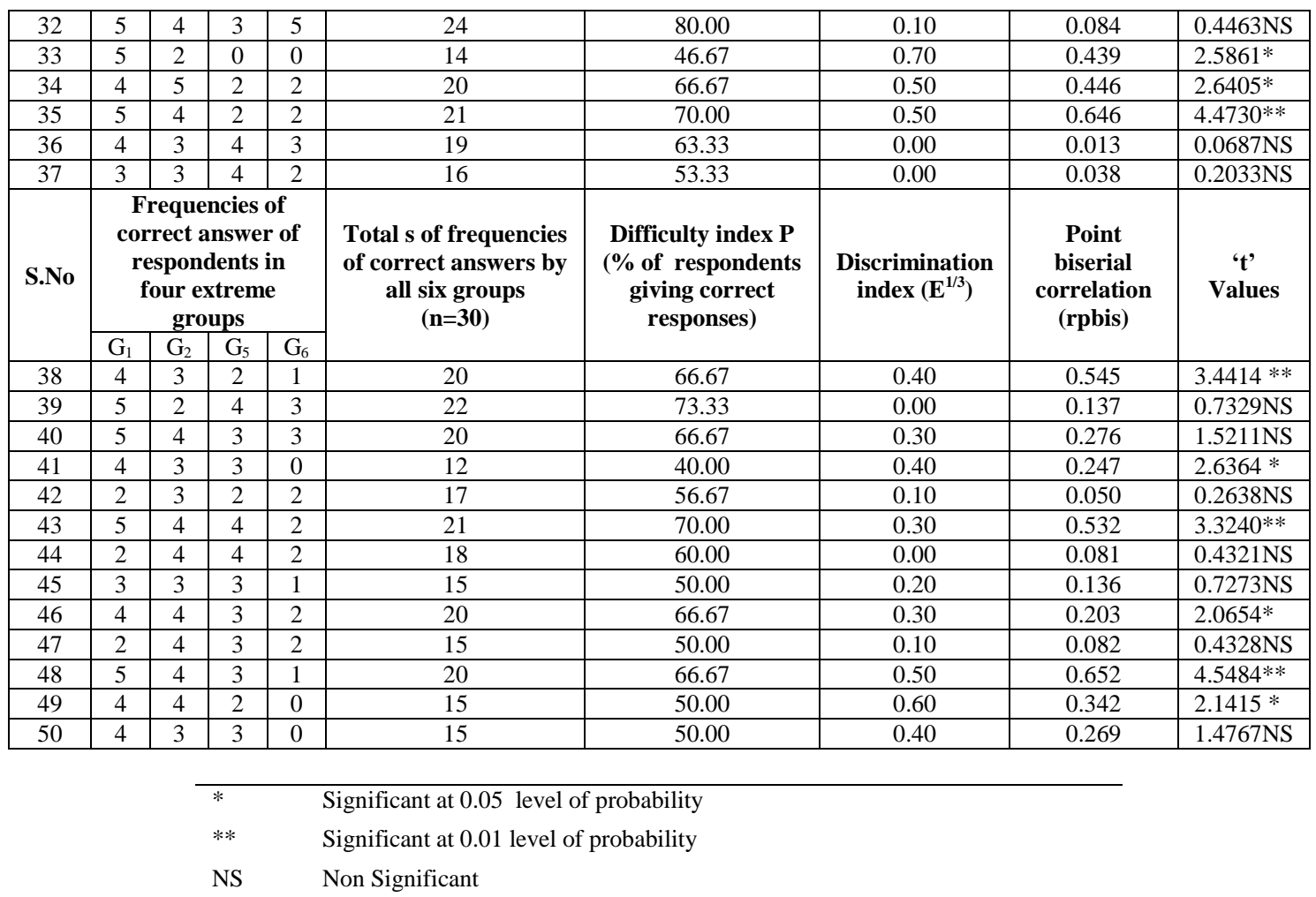

\section{Conclusion:}

The standard test conducted to measure the knowledge of cotton farmers on health hazards of pesticides usage is useful for the researcher to find out number of items actually related to measure the knowledge level of the cotton farmers.

\section{References:}

[1]. Bloom B S, Engelhardt M, Frust E, Hill and K Rathwal D R 1956 Taxonomy of educational objectives, The cognitive domain, Orient Longmans, New York.

[2]. Garrett H E 1966 Statistics in Psychology and Education. David McKay company Inc. and Longman Group Ltd., New York.

[3]. Gonard H S 1948 Characteristics and uses of items analysis of data. Psychological monograph.

\section{Appendix-I \\ Knowledge Of Cotton Farmers On Health Hazards Of Pesticides Usage Name Of The Respondent: \\ Village:}

\section{Please State Yes/No}

1.Pesticide residues are observed in the edible parts of the plant

2. It is important to shower and change clothes after handling pesticides

3. Protective clothing (gloves, shoes, long sleeves etc) should be worn when mixing (or) applying pesticides

4. It is important to read instructions/warning labels on pesticide containers

5 . Do you know about WHO pesticide classification

6. It is not good to apply pesticides on a windy day

7. Do you know about ETL (Economic Threshold Level)

$$
\begin{gathered}
\text { Yes/No } \\
\text { Yes/No } \\
\text { Yes/No } \\
\text { Yes/No } \\
\text { Yes/No } \\
\text { Yes/No } \\
\text { Yes/No } \\
\text { Yes/No } \\
\text { Yes/No } \\
\text { Yes/No } \\
\text { Yes/No }
\end{gathered}
$$$$
\text { of insect pests }
$$

8. Health effects of pesticide exposure may be inherited from one

generation to another generation

9. Pesticides should be stored out of reach of children and animals

10. Leaking pesticide containers (or) equipment should be replaced

(or) repaired

11. Eating, drinking (or) smoking in the field increases the possibility of pesticides entering the body 
12. Do you know about $\mathrm{LD}_{50}$ (Lethal Dosage) value

Yes/No

13. Do you follow recommended dosage for controlling the insect pest

Yes/No

14. Do you know that you should not enter the field after spraying

Yes/No

15. It is not good to store water in container that have been used for

Yes/No

storing pesticides

16. Do you spray pesticides weekly in your field

Yes/No

II. Please State True/False

17. Organophosphates insecticides are more harmful than that of organochlorine insecticides

18. Residual effects of pesticides causes soil pollution and decreases

the soil fertility

19. Empty pesticide containers cannot be kept for reuse

20. Pesticides can enter the body through skin and causes skin rashes

21. Pesticides should be sprayed only in the morning time

22. If pesticides come in contact with the eye, eye flushing should be done

23. Vomiting, diarrhoea, salivation and cramps are signs of pesticide poisoning

24. Proper training was received regarding spraying operation

25. Mild and moderate illness such as headaches and dizziness can happen after contact with pesticides

26. Victims who inhaled pesticides should be taken away from pesticide area to fresh air immediately

27. If you have come in contact with pesticides on your body, it is important to immediately remove the contaminated clothing and rinse skin with water

True/False

True/false

True/False

True/False

True/False

True/False

True/False

True/False

True/false

True/False

True/False

III. Fill in the blanks

28. Insecticide dosage used to control spotted boll worm is

29. Example for contact poison

30. Insecticide dosage used to control whitefly

31. Example for fumigant

IV. Choose the correct answer

32. Endosulfan is an

A.Organophosphate compound

C.Carbamate

B. Organochlorine compound

33. The blue colour symbol indicates the toxicity level of the chemical is ( )
A.Extremely toxic
B. Highly toxic
C.Moderately toxic
D. Low toxic

34.The red colour symbol indicates the toxicity level of the chemical is ( )
A.Extremely toxic
B. Highly toxic
C. Moderately toxic
D. Low toxic

35. The green colour symbol indicates the toxicity level of the chemical is ( )
A. Extremely toxic
B. Highly toxic
C. Moderately toxic
D. Low toxic
36.Phorate chemical is
B. Highly hazardous
A.Extremely hazardous
D. Slightly hazardous
37.Example for systemic insecticide
A.Acephate
B. Phosphomidon
C.Methyl demeton
D. All the above

38. The yellow colour symbol indicates the toxicity level of the chemical ( )
A.Extremely toxic
B. Highly toxic
C. Moderately toxic
D. Low toxic

39. Malathion chemical is

A.Extremely hazardous

B. Highly hazardous

C.Moderately hazardous

D. Slightly hazardous

40.What type of pesticide formulation do you use
A.Dust (or) Powder
B. Liquid spray
C. Granules
D. Others 
41.Type of sprayer used for spraying
A.Knapsack sprayer
B. Power sprayer
C.Any other
D. None

42. How do you measure the chemical to be used
A.With bottle tap/cap
B.Using measuring instrument
C.Any other
D. none

43. Where do you store pesticides
A.In kitchen
B. Anywhere in the house
C.In a separate place
D.Other places

44. Example for stomach poison

A.Calcium arsenate

B. Malathion

C.Acephate

D. DDT

45. Who in the family was affected with pesticide exposure
A.Yourself
B. Wife
C.Children
D. None

V. Answer the following:

46. What is the period of persistence of malathion chemical in the plant after spraying?

Ans:

47. Name the insecticides used in the cotton crop?

Ans:

48. What is the persistence period of imidachloprid chemical in the plant after spraying?

Ans:

49. What is the persistence period of synthetic pyrethroids in the plant after spraying?

Ans:

50. Insecticide used to control aphids?

Ans: 